\title{
ARTES DE CURAR, MEDICINA E SAÚDE PÚBLICA: UM OLHAR HISTORIOGRÁFICO LATINO-AMERICANO
}

\author{
André Mota* \\ Universidade de São Paulo \\ São Paulo - São Paulo - Brasil
}

Resenha do livro: CUETO, Marcos E PALMER, Steven. Medicina e saúde pública na América Latina: uma história. Rio de Janeiro: Ed. Fiocruz, 2016.

A doença pertence não só à história superficial dos progressos científicos e tecnológicos como também à história profunda dos saberes e das práticas ligadas às estruturas sociais, às instituições, às representações, às mentalidades.

Jacques Le Goff

A necessidade de se pautarem estudos do campo da saúde numa perspectiva histórica originou, nas últimas décadas, novos horizontes analíticos para as condições de emergência de saberes voltados à explicação do social na determinação de processos patológicos, bem como de práticas médicas e de saúde. Nesse quadro, a história estaria apta a compreender contextual e temporalmente as políticas de saúde e suas práticas confrontando novos

* Historiador, professor do Departamento de Medicina Preventiva e coordenador do Museu Histórico da Faculdade de Medicina da Universidade de São Paulo. E-mail: a.mota@fm.usp.br. 
temas, metodologias, problemas e alternativas que requalifiquem suas interpretações. Partindo, então, dessa necessidade da documentação mais ampla possível de vários tipos e origens (documentos institucionais, didático-pedagógicos ou iconográficos, registros de viajantes, religiosos, naturalistas e cronistas etc.) -, essa concepção de história da medicina e da saúde implicou a ampliação de métodos e quadros de análise, repercutindo os saberes e as práticas no campo da medicina e da saúde pública, assim como seus espaços institucionais de ensino, pesquisa e trabalho. Com a mesma força, ampliou as práticas e representações do homem comum e os espaços de associações profissionais, sociedades científicas e periódicos, sem perder de vista o universo popular, suas formas de organização e sua leitura do mundo que o cerca.

Essas são algumas das preocupações de Medicina e saúde pública na América Latina: uma historia, de Marcos Cueto e Steven Palmer. Com o objetivo de fazer um grande levantamento dos estudos latino-americanos em torno de temas da saúde pública e da medicina em cinco diferentes momentos históricos, os autores conseguiram estabelecer, com imensa competência, mais que um balanço historiográfico, uma nova perspectiva para o campo histórico, ao admitir a América Latina como um espaço geográfico e de sentidos, apontando aproximações e distanciamentos, rupturas e permanências, circularidades e particularidades, ou seja, eixos capazes de configurar tempos que indicam repercussões ora fragmentadas, ora identitárias. No caso brasileiro, em particular, seria impossível fugir da comparação com as nações estudadas. Segundo Prado:

...comparar o Brasil com os demais países da América Latina sempre me pareceu um desafio estimulante. Na medida em que a história de cada país latino-americano corre paralelamente às demais, atravessando situações sincrônicas bastante semelhantes a colonização ibérica, a independência política, a formação dos Estados nacionais, a preeminência inglesa e depois a norte-americana, para ficar nas temáticas tradicionais -, não há, do meu ponto de vista, como escapar às comparações. Em vez de manter os olhos fixos na Europa, é mais eficaz, para o historiador, olhar o Brasil ao lado dos países de colonização espanhola. ${ }^{1}$

O capítulo primeiro traz a dimensão colonial do processo americano entre os séculos XVI e XIX, apresentando as circularidades entre os conhecimentos médicos produzidos por universidades e escolas cirúrgicas e os sabe-

1 PRADO, Maria Ligia Coelho. Repensando a história comparada da América Latina. Revista de História, n. 153, 2005, p. 11-33. 
res e as artes de curar dos diversos grupos africanos, indígenas e europeus. Essa experiência, porém, sofreu uma ruptura importante com mudanças na organização social e política advindas dos movimentos de independência, que se opunham aos padrões vigentes e tentavam impor os seus próprios como elementos reafirmadores e diferenciadores entre os de fora e os de dentro do seu território, aglutinando o escol de diversas províncias em torno de ações que pretendiam demolir os alicerces que ainda restassem do sistema colonial.

Nesse movimento de interação e subjugação, os autores também discutem a forma como doenças novas e antigas se propagaram pelos territórios, atingindo colonizadores e colonizados, obrigando o próprio ordenamento colonial europeu a uma compreensão mais larga desses saberes produzidos, permitindo, inclusive, que se formasse uma mestiçagem médica. Sem dúvida, esse pluralismo se constituiu por toda a América, tendo suas bases sido corroídas com a chegada do pensamento iluminista às universidades e aos grupos corporativos, atacando os saberes populares por sua "falta de cientificidade" e seus divulgadores, majoritariamente curandeiros indígenas e africanos, como charlatães a ser combatidos em nome da ciência e dos interesses nacionais, que nasciam a partir do século XIX.

O segundo capítulo transpõe para a América Latina as mudanças trazidas pelo século XIX ao campo da medicina e da saúde pública. Sem fugir aos processos independentistas em curso na região, é relevante o estudo da conformação da corporação médica não apenas como formatadora de homens da ciência, mas também como preparadora de homens do poder político, questão central para os processos de criação das nações latino-americanas. Indo além, amplia-se o raio de visão sobre a produção de conhecimento no campo médico e de saúde pública pela criação de instituições de pesquisa e de formação profissional, colocando esses atores das Américas em contato internacional por meio de suas pesquisas e da relevância dessas instituições.

Ordenando esse pensamento, incorporaram-se a sociologia comtiana e os métodos experimentais de Claude-Bernard, por partirem, seja no campo sociológico ou médico, da classificação do ser humano e da sociedade segundo seu estado físico, intelectual e moral. Nesse sentido, coligiam-se o estado normal do indivíduo e da sociedade em função da maior ou menor manifestação de sintomas, que nada mais eram, de acordo com essa posição, que indícios de desvios patológicos. Esses desvios seriam balizados por um "estado-padrão normativo", uma ordem reguladora. Com vistas a "moldar" todos os homens pelas características preconizadas por dados padrões de normalidade, instituía-se outro conceito - o de saúde. Um homem normal seria, por excelência, saudável. Assim como a ciência e as práticas médicas, 
várias outras esferas da vida humana foram aderindo à busca dessa normalidade, que preconizava a preservação do corpo são e da mente sã.

Nessa composição de ações, o terceiro capítulo volta-se para algumas áreas centrais de conhecimento: a nova concepção que ganha a figura do médico, a partir da segunda metade do século XIX, como responsável pelo cuidado individual e coletivo de uma sociedade consumida por doenças e epidemias que avançam em todos os pontos em que o capitalismo finca suas fundações. Outro tema são as epidemias. Se elas sempre existiram na história da humanidade, esse foi um momento ímpar, devido a um deslocamento populacional nunca visto para regiões longínquas ou inóspitas, tidas como fontes exploradoras e produtivas. No caso latino-americano, a chamada medicina tropical foi um caso exemplar de construção teórica das doenças nesse território. Para atender à intenção dos europeus de dominar o território e promover a investigação científica de doenças desconhecidas, ela acabou ensejando o desenvolvimento de diversos centros de estudos e pesquisa e a formulação de várias teorias sobre a origem e a propagação de epidemias, além de uma mudança paradigmática da teoria miasmática aos germes. Tudo isso conduzido por um movimento de interiorização nascido da necessidade de domínio territorial, mas também científico, ou seja, descortina-se outra realidade nacional que afeta as narrativas nacionais. No caso latino-americano, diversas instituições europeias e estadunidenses se interessaram por essas questões, tendo sido a Fundação Rockefeller a que deixou marcas indeléveis por todo o século XX, quer na formação de profissionais capazes de compor um corpo técnico voltado aos problemas médicos e de saúde nacionais, quer na produção de conhecimento médico-científico pautado nessas mesmas descobertas.

O quarto capítulo discute o século XX da perspectiva das mudanças tecnológicas médicas e de saúde, desde as concepções eugenistas conformadas por uma ciência da raça até as críticas a seus pressupostos, que atravessaram diversos organismos que aderiram à internacionalização da medicina preventiva já francamente como movimento ideológico, o que sem dúvida afetou profundamente a eugenia e seus cânones. Foi nesse contexto que emergiu o ideário preventivista, a partir de três vertentes: a higiene no século XIX, ligada ao desenvolvimento do capitalismo e à ideologia liberal, a discussão dos custos da atenção médica nas décadas de 1930-40 nos EUA, já sob uma nova divisão internacional de poder e na própria dinâmica da Grande Depressão, que configuram o aparecimento do Estado interventor, e a redefinição das responsabilidades médicas, surgida no interior da educação médica. Suas diretivas ecoaram ao se discutir uma nova configuração da 
formação profissional, apregoada nos seminários de Viña de Mar, no Chile, em 1955, e de Tehuacán, no México, em 1956. A presença de brasileiros, entre eles muitos representantes de São Paulo, demonstrava seu grande interesse.

Por essa interpretação, interessava, sobretudo, verificar que a medicina preventiva, a medicina social e a medicina pública se mostravam mais seguras e positivas, por abrangerem a coletividade. Essa nova disposição médica relegou a eugenia a um pequeno alcance nacional. Assim, o preventivismo foi, sem dúvida, um movimento que ajudou a responder às necessidades econômicas do setor, ou seja, a baratear o sistema de saúde estatal, ao se debruçar sobre medidas de prevenção de caráter coletivo, e ao demonstrar politicamente que os países capitalistas se preocupavam com as demandas sociais que envolvem a saúde e a doença das populações.

Esse foi também um período de mudanças profundas, envolvendo cada vez mais campos técnico-científicos externos à medicina a partir das mudanças do campo da clínica no decorrer da segunda metade do século XX, em função de inúmeros e importantes desenvolvimentos em microbiologia, genética e farmacologia, assim como na aplicação médica de conhecimentos científicos e técnicos de outras áreas e que, pela legitimidade social dos valores que carregam e produzem, se transferem e se adaptam à área da saúde. Reflexo do salto tecnológico devido às descobertas médico-científicas aliadas às do campo farmacêutico - antibióticos, psicotrópicos e esteroides -, desenvolve-se nesses anos a crença na manutenção de certa prosperidade social do mundo ocidental pelo aumento da expectativa e pelo estilo de vida. Entraram na pauta médica e da saúde dos cidadãos temas até então ignorados como, por exemplo, o meio ambiente e a discussão sobre a poluição, a educação e a luta antitabagista e os cuidados voltados para a pobreza social. Essas questões exigiram uma revisão da própria formação médica e das instituições de saúde da época.

O debate internacional sobre a saúde e suas possíveis formas de mudança em relação à esfera social girava em torno do desenvolvimento das nações atrelado às cooperações internacionais. Para concretizar essas pretensões, organizou-se uma série de encontros e congressos com o objetivo de estruturar as diferentes visões daquelas correntes, com grande participação de pesquisadores e gestores latino-americanos. Esse processo foi fruto de uma agenda internacional proposta pela Organização Pan-Americana de Saúde (Opas) e pela Organização Mundial de Saúde (OMS), ambas interessadas em promover, num plano mais geral, atuações em saúde pública e na assistência médica individual, especialmente a partir da década de 1950, relativamente a: organização de serviços nacionais de saúde, zoonoses, saúde 
dos trabalhadores, saúde materno-infantil, migrações, alimentos, fármacos, saneamento básico e as relações entre a saúde pública e os seguros sociais.

O quinto e último capítulo, que se concentra a partir dos anos de $1960 \mathrm{e}$ 1970 até os atuais, é, pois, aquele em que as mudanças nas práticas em saúde rumam à segmentação dos conhecimentos e à complexa organização da produção dos serviços assistenciais, constituindo ramos progressivamente especializados e suas respectivas instituições, podendo se falar, inclusive, no estabelecimento de uma medicina tecnológica. Já o campo da saúde pública se ressentia da ausência do "médico sanitarista", entendido como um "profissional especializado" nessa área, passando, então, também ela a ser concebida como uma especialidade sobretudo médica.

O campo da saúde vai compondo uma estrutura não reconhecida em todos os países, porquanto constituída a partir de dois subcampos de conhecimento: a medicina, com a assistência individual aos usuários de serviços de saúde, e a saúde pública, com intervenção em populações ou coletividades e no meio ambiente. Com a divulgação da noção de atenção primária à saúde (APS) na Conferência de Alma-Ata, em 1978, a OMS conclamou os países a redirecionarem seu sistema de saúde para dar atenção ao conjunto da população, assinalando que a viabilidade da extensão estava na adoção da estratégia da APS.

Com a emergência da ideia de APS e sua articulação com a meta de saúde para todos no ano 2000 (SBT-2000), tema que os autores mostram como um espaço de luta política em torno de concepções diferentes sobre seu significado e raio de ação, foram reconhecidos princípios que a deslocariam de cuidados primários para atenção primária, fazendo corresponder àqueles o conteúdo de ações técnicas e a esta um nível de atenção, ou a porta de entrada para um sistema hierarquizado e regionalizado de saúde, o que caracterizaria uma inflexão histórica no conceito de APS. Pode-se dizer que essa expansão conceitual já vinha sendo processada desde meados da década de 1970, tendo a chamada reforma sanitária assumido um espaço inédito para sua consecução. O trabalho de Cueto e Palmer é da maior relevância, por tratar com extrema competência a participação de diversos atores e instituições em diversos países latino-americanos, quer na introdução da APS em seus territórios, gerando experiências compartilhadas em torno da saúde como um direito e extensivo a toda a população, quer criticando as interpretações que a defendiam e que, afastando-se dos lemas apregoados por Alma-Ata, propõem uma tecnologia simplificada de saúde para pobres, com ações verticais resumidas ao controle de crescimento e imunização.

Estendendo-se aos dias atuais, esse debate trouxe experiências centrais para todo o território latino-americano, como, por exemplo, a erradicação da 
varíola e da poliomielite. Graças às estratégias lançadas pela OMS e às políticas estatais locais entrelaçadas aos níveis primários de atenção, foi possível identificar essas duas doenças e controlá-las vigorosamente nos anos 1980, quando há uma inflexão na discussão sobre o direito à saúde e sua cobertura populacional. Contudo, se os discursos do campo médico e de saúde pública formulados nos anos 1960-70 se jactavam de ter todas as doenças sob seu conhecimento e domínio, nenhuma causou tanta angústia e fascínio como a Aids, ao misturar os medos e os tabus milenares de epidemias à homossexualidade e à morte. Na primeira década da epidemia, essa doença se contrapôs duramente ao saber médico que a sociedade moderna, científica e técnica já considerava ilimitado. Assim, sua história foi reveladora de tensões de uma sociedade em que se discutiam várias esferas constitutivas tanto do processo epidêmico quanto das dimensões individuais da contaminação e, naquele momento, com grande espaço para o adoecimento. Sem dúvida, o tema também aponta mudanças contextuais em torno da concepção de saúde e do raio de sua ação em âmbito estatal ou privado.

Os autores localizam os dilemas da sociedade que, desde os anos 1990, vêm sendo marcados pelo discurso liberal e por uma retórica oligárquica, reforçados ambos por propostas reformistas orientadas para o mercado, ganhando realce a ideia de que a expansão do Estado constituiria um aumento supérfluo dos gastos públicos, com inchaço da burocracia e desperdício de recursos. Nesse diapasão, a democracia representativa seria absolutamente dispensável, quando não apontada como uma ameaça aos novos valores do capital, numa compulsão, principalmente dos grupos ligados ao capital financeiro e a seus interesses, de se livrar do povo e da política, passando a atacar, como numa guerra, a ideia de Estado-providência, com o fim de qualquer situação de assistência estatal, imputando aos indivíduos e a suas iniciativas particulares o único meio de se alcançar o bem comum, por mais contraditório que isso seja.

No âmbito internacional, os processos que envolvem adoecimentos e formas de cura deixam de ser considerados saúde internacional e passam a ser saúde global, indicando as mudanças trazidas pelo neoliberalismo e as mudanças da conceituação de Estado. Como mostram Cueto e Palmer, enquanto a primeira expressão designa atividades e necessidades de saúde pública coordenadas por Estados-nações, a segunda trata mais diretamente dos desafios transnacionais em saúde, que ultrapassariam as funções e o controle dos Estados. Mais do que isso, também têm grande impacto as políticas econômicas alicerçadas em acordos firmados pelo Banco Mundial, pelo Fundo Monetário Internacional e pelo Banco Interamericano de Desenvolvimento, 
além de interesses de países ricos como os EUA. Nesse sentido, a garantia da saúde exige pagamento por serviços de saúde que gozam de excelência no caso dos seguros de saúde e das instituições conveniadas destinadas a parcelas da classe média e à classe alta, mas que, no caso de todos os outros estratos da população trabalhadora, são no mais das vezes apenas sofríveis.

Finalmente é a população mais pobre e marginalizada que padece na ausência do Estado, sem garantia de condições mínimas de saúde, desaguando em altos níveis de mortalidade materna, na primeira infância e de idosos. As saídas alternativas encontradas desde os anos 1960 em vários desses países, inclusive no Brasil, com a criação do Sistema Único de Saúde em 1988, encerram as reflexões desse importante estudo, chamando atenção para os dilemas que cercam o mundo global, numa espiral em que a América Latina vem ganhando destaque. Ao leitor, uma obra que transforma a visão sobre o passado ao considerar que o sofrimento humano e as formas de dirimi-lo ou acolhê-lo sempre se refletirão no poder, na luta cotidiana e na certeza de que a história da medicina e da saúde pública se move não apenas entre avanços científicos e tecnológicos, mas também entre as condições humanas e suas formas de interação. 